\title{
Variability in MRI vs. ultrasound measures of prostate volume and its impact on treatment recommendations for favorable-risk prostate cancer patients: a case series
}

Yonina R Murciano-Goroff ${ }^{1,2,3}$, Luciant D Wolfsberger ${ }^{1,2}$, Arti Parekh ${ }^{1,2}$, Fiona M Fennessy ${ }^{1,2,3}$, Kemal Tuncali, ${ }^{1,2,3}$, Peter F Orio III 1,2,3, Thomas R Niedermayr ${ }^{1,2,3}$, W Warren Suh ${ }^{4}$, Phillip M Devlin ${ }^{1,2,3}$, Clare Mary C Tempany ${ }^{1,2,3}$, Emily H Neubauer Sugar ${ }^{1,2}$, Desmond A O'Farrell ${ }^{1,2}$, Graeme Steele ${ }^{1,2,3}$, Michael O'Leary ${ }^{1,2,3}$, Ivan Buzurovic ${ }^{1,2}$, Antonio L Damato ${ }^{1,2}$, Robert A Cormack ${ }^{1,2}$, Andriy Y Fedorov ${ }^{1,3}$ and Paul L Nguyen ${ }^{1,2,3^{*}}$

\begin{abstract}
Background: Prostate volume can affect whether patients qualify for brachytherapy (desired size $\geq 20 \mathrm{~mL}$ and $\leq 60 \mathrm{~mL}$ ) and/or active surveillance (desired PSA density $\leq 0.15$ for very low risk disease). This study examines variability in prostate volume measurements depending on imaging modality used (ultrasound versus MRI) and volume calculation technique (contouring versus ellipsoid) and quantifies the impact of this variability on treatment recommendations for men with favorable-risk prostate cancer.
\end{abstract}

Methods: We examined 70 patients who presented consecutively for consideration of brachytherapy for favorable-risk prostate cancer who had volume estimates by three methods: contoured axial ultrasound slices, ultrasound ellipsoid (height $\times$ width $\times$ length $\times 0.523$ ) calculation, and endorectal coil MRI (erMRI) ellipsoid calculation.

Results: Average gland size by the contoured ultrasound, ellipsoid ultrasound, and erMRI methods were 33.99, 37.16, and $39.62 \mathrm{mLs}$, respectively. All pairwise comparisons between methods were statistically significant (all $p<0.015)$. Of the 66 patients who volumetrically qualified for brachytherapy on ellipsoid ultrasound measures, 22 (33.33\%) did not qualify on ellipsoid erMRI or contoured ultrasound measures. 38 patients (54.28\%) had PSA density $\leq 0.15 \mathrm{ng} / \mathrm{dl}$ as calculated using ellipsoid ultrasound volumes, compared to 34 (48.57\%) and 38 patients (54.28\%) using contoured ultrasound and ellipsoid erMRI volumes, respectively.

Conclusions: The ultrasound ellipsoid and erMRI ellipsoid methods appeared to overestimate ultrasound contoured volume by an average of $9.34 \%$ and $16.57 \%$ respectively. $33.33 \%$ of those who qualified for brachytherapy based on ellipsoid ultrasound volume would be disqualified based on ultrasound contoured and/or erMRI ellipsoid volume. As treatment recommendations increasingly rely on estimates of prostate size, clinicians must consider method of volume estimation.

Keywords: Prostate volume, Favorable-risk prostate cancer, Brachytherapy, Active surveillance, MRI, Ultrasound

\footnotetext{
* Correspondence: Pnguyen@lroc.harvard.edu

'Brigham and Women's Hospital, Radiation Oncology, 75 Francis Street, Boston, MA 02115, USA

${ }^{2}$ Dana-Farber Cancer Institute, 50 Brookline Avenue, Boston, MA 02115, USA

Full list of author information is available at the end of the article
} 


\section{Background}

Eligibility for both brachytherapy [1] and active surveillance in men with favorable-risk prostate cancer is partially dependent on determination of prostate volume [2]. Desired volumes for brachytherapy are typically cited as $\geq 20 \mathrm{~mL}$ [3-5] and $\leq 60 \mathrm{~mL}$ [1], while classification into the "very low-risk" group that is often offered active surveillance requires a PSA density of $\leq 0.15 \mathrm{ng} / \mathrm{dl}$, calculated on the basis of measured prostate volume [2]. Despite the dependence of treatment recommendations on prostate volume, the method by which the volume should be estimated is rarely specified in guidelines.

Three major techniques are currently in widespread use to determine prostate size. From a transrectal ultrasound (TRUS), volume can be estimated via the traditional ellipsoid estimation based on the height $(\mathrm{H})$, width (W), and length (L) of the prostate, using the formula: $\mathrm{H} \times \mathrm{W} \times \mathrm{L} \times 0.523$. Alternatively, the same TRUS can be contoured on multiple axial slices (of thickness typically between $2.5 \mathrm{~mm}$ and $5 \mathrm{~mm}$ ) during a brachytherapy volume study and then integrated in $3 \mathrm{D}$ space to generate a contoured volume estimate. Finally, MRIs are being increasingly used to stage prostate cancer and commonly report volume estimates based on the ellipsoid formula.

There have been some studies examining the differences between the volume estimates of these various modalities [6-11], but currently it is unknown whether differences in the methods of volume determination could translate into differences in treatment recommendations for favorable-risk patients.

Therefore, our study aimed to assess whether differences in prostate volume as estimated by use of the ellipsoid formula based on TRUS measurements, contouring on TRUS, and use of the ellipsoid formula based on measurements from endorectal coil MRI (erMRI) would have implications for the determination of the eligibility of men with favorable-risk prostate cancer for either brachytherapy or active surveillance.

\section{Methods}

Institutional Review Board approval was obtained from the Dana-Farber Cancer Institute. The study examined 70 men who presented consecutively to one of the authors (PLN, Dana-Farber Cancer Institute) for consideration of brachytherapy for the treatment of favorable risk prostate cancer and had three estimates of prostate volume from the ellipsoid TRUS method, contoured TRUS method, and ellipsoid erMRI method with available MRI dimensions.

From an initial pool of 90 consecutive men, eight men who received Dutasteride or Androgen Deprivation Therapy were excluded from consideration owing to the role of these therapies in altering prostate size, as was the one individual who presented for consideration of salvage, rather than first-line, therapy. Patients who did not have all three measures of volume or for whom erMRI height, width, and length measures were not available $(\mathrm{n}=11)$ were excluded, leaving 70 patients for whom all data was available.

All individuals included in the analysis underwent prostate volume studies between August 2009 and June 2011. Volume studies typically included 3 separate volume estimates made at the time of presentation, and typically occurred on the same day. Ultrasound studies were performed in the dorsal lithotomy position with a BK probe ${ }^{\bullet}$ (BK Medical, Peabody, MA) connected to a Nucletron FIRST system with SPOT-PRO v3.1 ${ }^{\mathrm{Tm}}$ (Nucletron, an Elekta company, Elekta AB, Stockholm, Sweden) for acquiring ultrasound information in the sagittal plane and generating a 3D reconstruction for axial contouring. Volume was evaluated according to the ellipsoid method, in which height, width, and length were used to calculate overall gland volume based on the standard BK ultrasound prostate volume formula, namely $\mathrm{H} \times \mathrm{W} \times \mathrm{L} \times 0.523$. Contouring was done on the reconstructed ultrasound axial slices (2.5 mm thickness), and was also used to estimate volume based on an integration of the slices by the FIRST system (Nucletron, an Elekta Company). Additionally, patients underwent a 3Tesla multiparametric T2 erMRI, from which prostate volume was calculated using the standard MRI ellipsoid formula of $\mathrm{H} \times \mathrm{W} \times \mathrm{L} \times 0.523$.

Desired size for brachytherapy was taken to be between $\geq 20 \mathrm{~mL}$ [3-5] and $\leq 60 \mathrm{~mL}$ [1]. PSA densities were calculated using the latest PSA values available at the time of consideration for brachytherapy. Absolute PSA was divided by measured gland volume to obtain density. In keeping with the National Comprehensive Cancer Network (NCCN) Guidelines * (NCCN, Fort Washington, PA), PSA density of $\leq 0.15$ was regarded as a cut-off for the "very low risk" group that is typically offered active surveillance [2].

Prostate volumes and PSA densities obtained using the different calculations of gland size were compared using standard, paired t-tests carried out with STATA software. P-values of less than 0.05 were said to reflect statistical significance.

\section{Results}

Variation in Prostate Size by Method of Estimation

Estimates of prostate volume differed when disparate scanning modalities were used. Average gland size calculated by the contoured ultrasound, ellipsoid ultrasound, and erMRI methods were 33.99, 37.16, and $39.62 \mathrm{mLs,}$ respectively. The difference between the average volume obtained on contoured ultrasound and that obtained on ellipsoid ultrasound was significant $(\mathrm{p}=0.00)$ (Figure 1) 


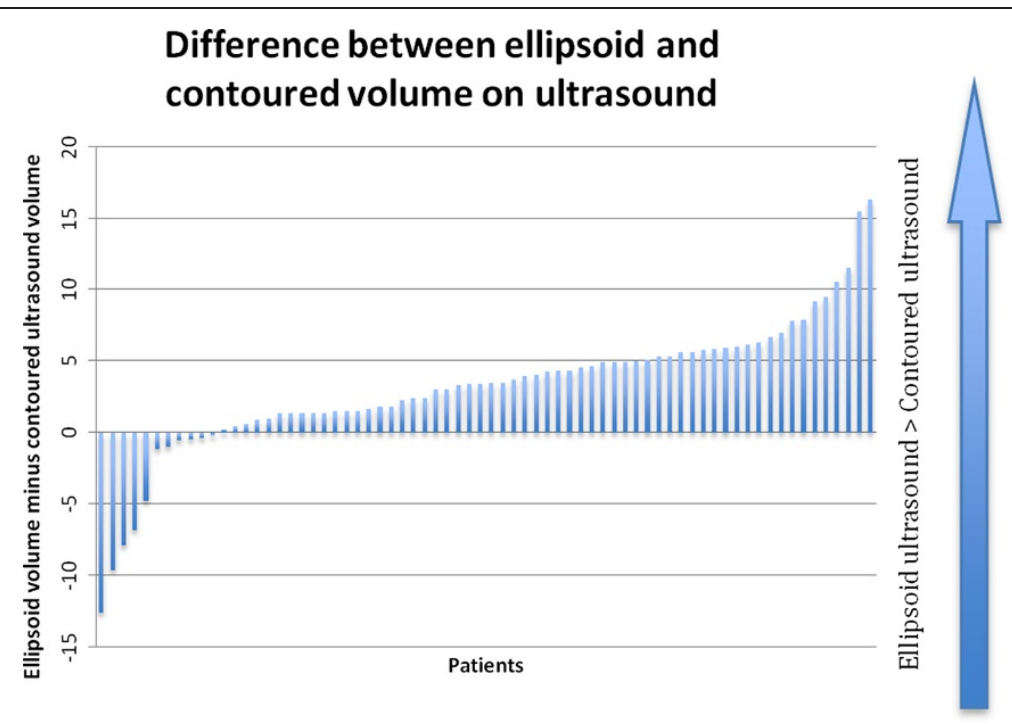

Figure 1 Differences in prostate volume measures using ellipsoid ultrasound versus contoured ultrasound.

as was the difference between average gland size on contoured ultrasound and erMRI $(\mathrm{p}=0.00)$. The comparison between average ellipsoid and erMRI prostate volumes was also significant $(\mathrm{p}=0.01)$ (Figure 2).

\section{Impact of Estimation Method on Qualification for Brachytherapy}

Different numbers of patients fit the prostate volume eligibility criteria for brachytherapy when disparate scanning modalities were used to calculate gland size. Of the 70 patients examined, all except 4 were eligible for brachytherapy when prostate volumes were calculated using the ellipsoid ultrasound method (desirable volume $\geq 20 \mathrm{~mL}$ and $\leq 60 \mathrm{~mL}$ ). Of the 4 patients deemed ineligible on ellipsoid ultrasound measures, 2 (50\%) met eligibility criteria for brachytherapy based on erMRI measures of volume.

Among the remaining 66 patients deemed anatomical candidates for brachytherapy based on ellipsoid ultrasound measures (size $\geq 20 \mathrm{~mL}$ and $\leq 60 \mathrm{~mL}$ ), 22 (33.33\%) did not qualify for brachytherapy based on volumes measured using one or both of the other scanning modalities. In particular, 16 patients would not have qualified on erMRI ( 6 patients $<20 \mathrm{~mL}, 10$ patients $>60 \mathrm{~mL}$ ) and 10 patients would not have qualified based on contoured ultrasound measures ( 7 patients $<20 \mathrm{~mL}, 3$ patients $>60 \mathrm{~mL}$ ).
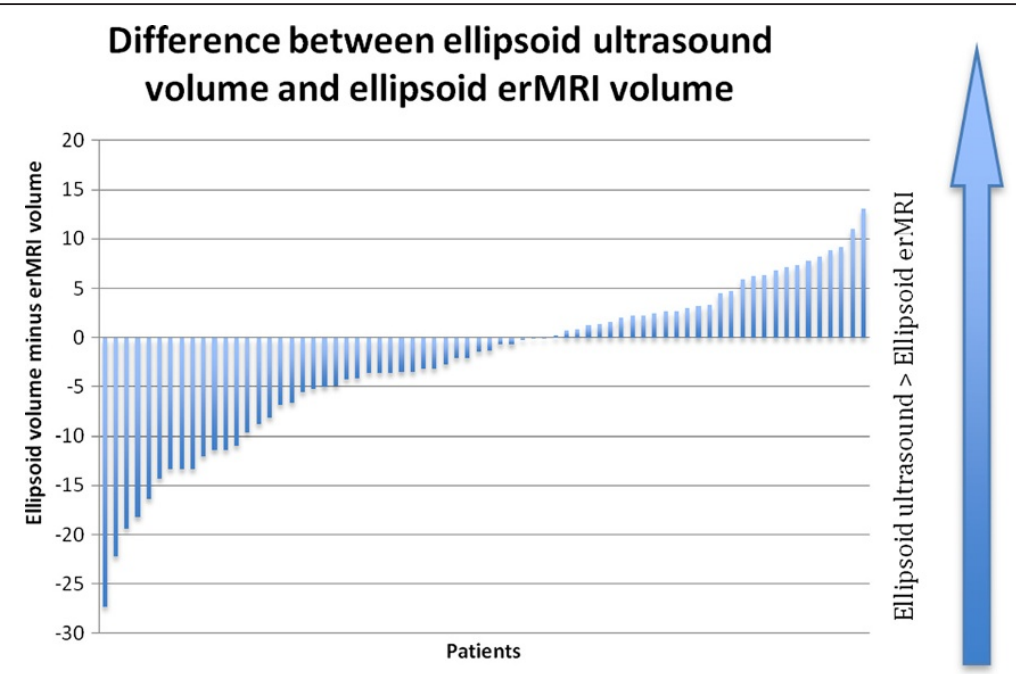

Figure 2 Differences in prostate volume measures using ellipsoid ultrasound and erMRI. 
6 of the 66 patients who were considered candidates for brachytherapy as determined by the ellipsoid ultrasound technique for measuring prostate volume had prostates $<20 \mathrm{~mL}$ on erMRI (9.09\%) and 10 patients had glands measuring $>60 \mathrm{~mL}$ on erMRI $(15.15 \%)$. 7 of the 66 patients who were anatomically good candidates for brachytherapy on ellipsoid ultrasound had prostate sizes $<20 \mathrm{~mL}(10.61 \%)$ on contoured ultrasound, and 3 patients had volumes $>60 \mathrm{~mL}(4.55 \%)$.

In total, the management of $24 / 70$ patients (34.29\%) would have changed if patient prostate size had been measured by a method other than ellipsoid TRUS (Figure 3).

\section{Impact of Estimation Method on PSA Density}

Each of the different scanning modalities was also used to calculate a PSA density. Using ellipsoid ultrasound volumes, 38 patients $(54.28 \%)$ had a PSA density $\leq 0.15 \mathrm{ng} / \mathrm{dl}$, which is the cut-off for the very low-risk group that is commonly offered active surveillance [2]. When volume was determined by erMRI, 34 patients (48.57\%) were deemed to have PSA density $\leq 0.15 \mathrm{ng} / \mathrm{dl}$, while 38 patients $(54.28 \%)$ were categorized as having PSA density $\leq 0.15 \mathrm{ng} / \mathrm{dl}$ using contoured ultrasound estimates of volume.

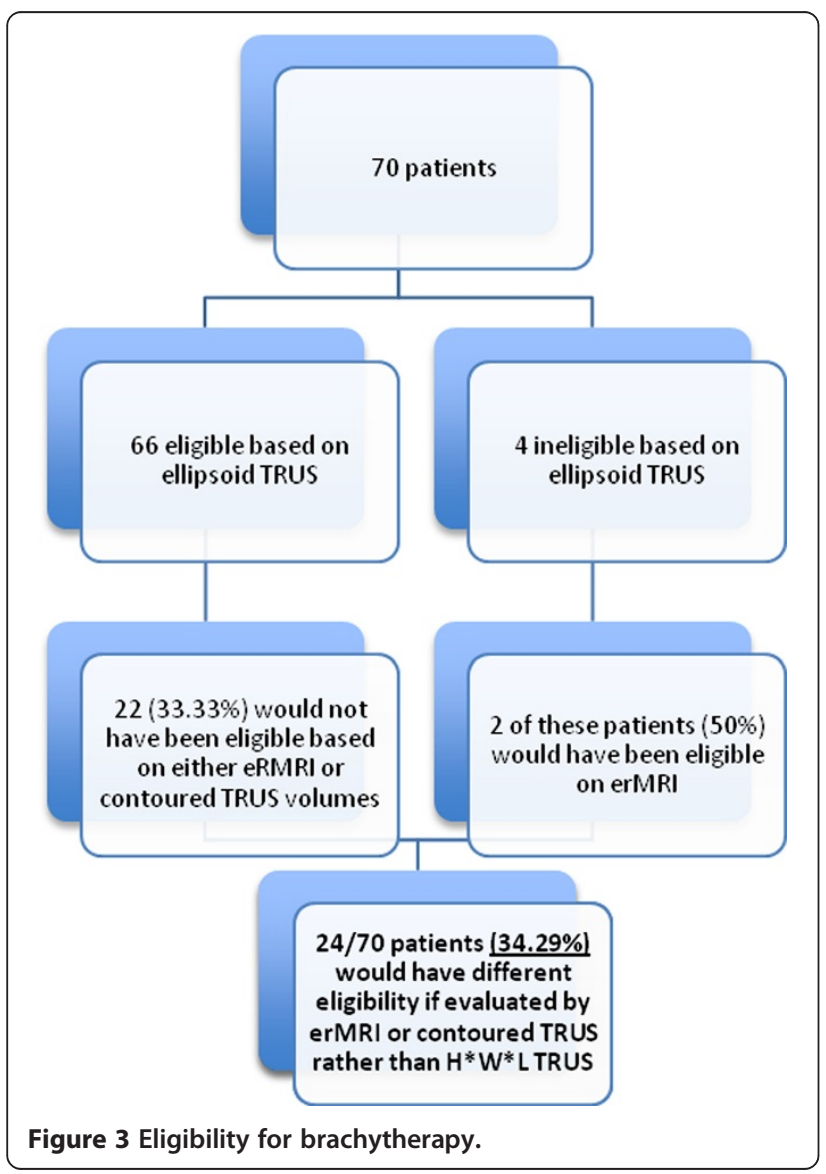

\section{Discussion}

Determination of eligibility for brachytherapy generally relies on prostate volume based criteria [1,3-5], but there are no agreed upon guidelines for how volume should be measured. Studies have examined the potential impact of large gland size on accurate dosimetry [12], pubic arch interference $[13,14]$, as well as urinary retention [12,14-16]. The technical feasibility of accurate dosimetry and effective outcomes [6,13,17-19] in men with smaller prostates who receive brachytherapy has also been analyzed. Previous studies of the impact of prostate volume on brachytherapy dosimetry and complication rates have used numerous methods to determine volume, including contoured TRUS [14-16,18,20], ellipsoid TRUS [21], and MRI [22,23].

In our study, the ellipsoid ultrasound and ellipsoid erMRI methods overestimated TRUS contoured volume by an average of $9.34 \%$ and $16.57 \%$, respectively. These results reflect the fact that no prostate is an exact ellipsoid, and while formulas based solely on height, width, and length are very convenient, they can only approximate the volume. Contouring on thinly cut axial slices can account for variability in prostate shape from the base to the apex [24].

While previous studies of volume estimation in brachytherapy candidates have shown smaller differences between TRUS and MRI-based estimations than our findings [7-9], most studies have compared TRUS to contoured MRI, which is less clinically practical than using an ellipsoid estimation of volume on MRI. The one study to compare volumes derived from contouring on TRUS with ellipsoid MRI volumes in 15 patients who were not receiving hormone therapy found a correlation between volumes of $r=0.83$ [10].

In our study, volumes estimated by erMRI were larger than those calculated on TRUS by either contouring or the ellipsoid method. These results may reflect the fact that MRI enables better soft tissue density determination, leading to greater maximal dimension estimates and inflating calculated volume estimates. It may also reflect the fact that on MRI, transagittal cuts are sometimes used for height estimates, rather than the transaxial cuts used on TRUS. Previous work has demonstrated that such a distinction in means of measuring height can alter volume estimates [25].

Our study is unique in that it may be the first to quantify the impact of differences in volumes derived from disparate scanning modalities on decision-making surrounding candidacy for brachytherapy. Of patients who qualified for brachytherapy based on the commonly used ellipsoid ultrasound technique for volume estimation, $33.33 \%$ would not have qualified for brachytherapy were they assessed using ultrasound contoured and/or erMRI estimated volumes. Management of $34.29 \%$ of patients 
would have changed had volume been determined by a method other than ellipsoid TRUS.

We also examined the impact of different volume measures on patients' eligibility for active surveillance based on standard PSA density criteria (desired PSA density $\leq 0.15 \mathrm{ng} / \mathrm{dl}$ ), and found that while $54.28 \%$ of patients were eligible using ellipsoid TRUS measures, $54.28 \%$ and $48.57 \%$ were eligible using erMRI and contoured ultrasound measures, respectively. The one previous study of active surveillance eligibility demonstrated that of five patients who were initially enrolled in an active surveillance program but were found to be ineligible based on contoured MRI, one patient (20\%) would still have been eligible based on ellipsoid TRUS [11]. Our study differs in our use of ellipsoid rather than contoured MRI as well as the diversity of our cohort, which was not limited solely to patients already enrolled in an active surveillance program.

The practical implications of our study are that clinicians should be aware that volume estimates of prostate size can vary significantly depending on how the estimate was obtained, and so when treatment decisions are highly dependent on prostate size, it may be worthwhile to consider the source of the estimate and how close the estimate sits to the boundary of a clinical guideline. For example, a patient with a prostate size of $70 \mathrm{cc}$ estimated on a prostate MRI who is otherwise a great candidate for brachytherapy might only have a volume of $55 \mathrm{cc}$ on a contoured ultrasound.

While our study is the largest to examine differences in prostate volume among brachytherapy candidates using disparate imaging modalities, it also has certain limitations. First, all cases were drawn from a single medical center with imaging carried out and interpreted at the center. Secondly, the ultrasound and erMRI scans done on our patients were not all carried out at precisely the same time, leading to possible confounding by bladder filling. However, scans were typically performed on the same day and endorectal coil was used in an effort to improve the accuracy of all MRI scans [26,27].

\section{Conclusions}

Our results point to significant differences in treatment recommendations depending on which imaging modality is used. In patients in whom prostate volume measurements or PSA density numbers are borderline for eligibility for brachytherapy or active surveillance, clinicians may wish to consider the possibility that disparate scanning modalities could yield different volume estimates. As treatment recommendations increasingly depend on prostate size, clinicians will need to take into account the method by which volume was estimated in determining treatment plans.

\section{Abbreviations}

erMRI: Endorectal coil MRl; TRUS: Transrectal ultrasound; H: Height; W: Width; L: Length.

\section{Competing interests}

PMD receives textbook royalties from Wolters Kluwer Publishing, Inc. He is also the Secretary Treasurer of ASTRO and the President of the Massachusetts Radiological Society, Inc.

\section{Authors' contributions}

YRMG created the patient database, carried out the statistical analysis, and drafted the manuscript. LW, AP, and WWS aided in patient data acquisition and interpretation, as well as study design. FMF, KT, PFO, TRN, CMCT, ALD, RAC, and AYF participated in data acquisition as well as interpretation and helped draft the manuscript. PD, EHNS, DAO, GS, MO, and IB were involved in data acquisition and interpretation. PLN conceived of the study, participated in its design and coordination, aided in patient data acquisition and interpretation, as well as in drafting the manuscript. All authors read and approved the final manuscript.

\section{Acknowledgments}

This project was made possible by funding from: An Anonymous Family Foundation; David and Cynthia Chapin; a Harvard Medical School Research Grant; and the Prostate Cancer Foundation.

\section{Author details}

'Brigham and Women's Hospital, Radiation Oncology, 75 Francis Street, Boston, MA 02115, USA. ${ }^{2}$ Dana-Farber Cancer Institute, 50 Brookline Avenue, Boston, MA 02115, USA. ${ }^{3}$ Harvard Medical School, 25 Shattuck Street, Boston, MA 02115, USA. ${ }^{4}$ Cancer Center of Santa Barbara, 519 W. Junipero Street, Santa Barbara, CA 93105, USA.

Received: 27 June 2014 Accepted: 2 September 2014

Published: 9 September 2014

\section{References}

1. Davis BJ, Horwitz EM, Lee WR, Crook JM, Stock RG, Merrick GS, Butler WM, Grimm PD, Stone NN, Potters L, Zietman AL, Zelefsky MJ, American Brachytherapy Society: American Brachytherapy Society consensus guidelines for transrectal ultrasound-guided permanent prostate brachytherapy. Brachytherapy 2012, 11:6-19.

2. Mohler JL, Kantoff PW, Armstrong AJ, Bahnson RR, Cohen M, D'Amico AV, Eastham JA, Enke CA, Farrington TA, Higano CS, Horwitz EM, Kane CJ, Kawachi MH, Kuettel M, Kuzel TM, Lee RJ, Malcom AW, Miller D, Pilmack ER, Pow-Sang JM, Raben D, Richey S, Roach M 3rd, Rohren E, Rosenfeld S, Schaeffer E, Small EJ, Sonpavde G, Srinivas S, Stein C, et al: Prostate cancer, version 2.2014. J Natl Compr Canc Netw 2014, 12:686-718.

3. Loblaw DA, Wallner K, Dibiase S, Russell K, Blasko J, Ellis W: Brachytherapy in patients with small prostate glands. Tech Urol 2000, 6:64-69.

4. Merrick GS, Butler WM, Dorsey AT, Lief JH: Effect of prostate size and isotope selection on dosimetric quality following permanent seed implantation. Tech Urol 2001, 7:233-240.

5. Nguyen PL, Chen MH, Choueiri TK, Hoffman KE, Hu JC, Martin NE, Beard CJ, Dosoretz DE, Moran BJ, Katin MJ, Braccioforte MH, Ross R, Salenius SA, Kantoff PW, D'Amico AV: Risk of all-cause and prostate-specific mortality after brachytherapy in men with small prostate size? Int I Radiat Oncol Biol Phys 2011, 79:1318-1322.

6. Rahmouni A, Yang A, Tempany CM, Frenkel T, Epstein J, Walsh P, Leichner PK, Ricci C, Zerhouni E: Accuracy of in-vivo assessment of prostatic volume by MRI and transrectal ultrasonography. J Comput Assist Tomogr 1992, 16:935-940.

7. Albert JM, Swanson DA, Pugh TJ, Zhang M, Bruno TL, Kudchadker RJ, Frank SJ: Magnetic resonance imaging-based treatment planning for prostate brachytherapy. Brachytherapy 2013, 12:30-37.

8. Tanaka O, Hayashi S, Matsuo M, Nakano M, Kubota Y, Maeda S, Ohtakara K, Deguchi T, Hoshi H: MRI-based preplanning in low-dose-rate prostate brachytherapy. Radiother Oncol 2008, 88:115-120.

9. Liu D, Usmani N, Ghosh S, Kamal W, Pedersen J, Pervez N, Yee D, Danielson B, Murtha A, Amanie J, Sloboda RS: Comparison of prostate volume, shape, and contouring variability determined from preimplant magnetic resonance and transrecetal ultrasound images. Brachytherapy 2012, 11:284-291. 
10. Cheah NLC, Michaelides D, Kong PK, Wyatt R, El-Modir A: Magnetic resonance imaging prostate volumes could be used as a surrogate for transrectal ultrasound volumes in estimating iodine-125 seeds required in brachytherapy. Clin Oncol (R Coll Radiol) 2009, 21:76.

11. Dianat SS, Rancier Ruiz RM, Bonekamp D, Carter HB, Macura KJ: Prostate volumetric assessment by magnetic resonance imaging and transrectal ultrasound: impact of variation in calculated prostate-specific antigen density on patient eligibility for active surveillance program. $J$ Comput Assist Tomogr 2013, 37:589-595.

12. Crook J, McLean M, Catton C, Yeung I, Tsihlias J, Pintilie M: Factors influencing risk of acute urinary retention after TRUS-guided permanent prostate seed implantation. Int J Radiat Oncol Biol Phys 2002, 52:452-460.

13. Bellon J, Wallner K, Ellis W, Russell K, Cavanagh W, Blasko J: Use of pelvic CT scanning to evaluate pubic arch interference of transperineal prostate brachytherapy. Int J Radiat Oncol Biol Phys 1999, 43:579-581.

14. Wang H, Wallner K, Sutlief S, Blasko J, Russell K, Ellis W: Transperineal brachytherapy in patients with large prostate glands. Int J Cancer (Radiat Oncol Invest) 2000, 90:199-205.

15. Liu HW, Malkoske K, Sasaki D, Bews J, Demers A, Nugent Z, Ong A, Bashir B, Dufan T, Cho P, Drachenberg D, Chowdhury A: The dosimetric quality of brachytherapy implants in patients with small prostate volume depends on the experience of the brachytherapy team. Brachytherapy 2010, 9:202-207.

16. Locke J, Ellis W, Wallner K, Cavanagh W, Blasko J: Risk factors for acute urinary retention requiring temporary intermittent catheterization after prostate brachytherapy: a prospective study. Int I Radiat Oncol Biol Phys 2002, 52:712-719.

17. Mayadev J, Merrick GS, Reed JR, Butler WM, Galbreath RW, Allen ZA, Wallner KE: Permanent prostate brachytherapy in prostate glands $<20 \mathrm{~cm}^{3}$. Int J Radiat Oncol Biol Phys 2010, 76:1450-1455.

18. Kovtun KA, Wolfsberger L, Niedermayer T, Sugar EN, Graham PL, MurcianoGoroff Y, Beard C, D'Amico AV, Martin NE, Orio PF, Nguyen PL: Dosimetric quality and evolution of edema after low-dose-rate brachytherapy for small prostates: implications for the use of newer isotopes. Brachytherapy 2014, 13:152-156.

19. Chung E, Stenmark S, Evans C, Narayana V, McLaughlin PW: Greater postimplant swelling in small-volume prostate glands: Implications for dosimetry, treatment, planning and operating room technique. Int J Radiat Oncol Biol Phys 2012, 82:1944-1948.

20. McNeely LK, Stone NN, Presser J, Chircus JH, Stock RG: Influence of prostate volume on dosimetry results in real-time ${ }^{25}$ I seed implantation. Int J Radiat Oncol Biol Phys 2004, 58:292-299.

21. Stone NN, Stock RG: Prostate brachytherapy in patients with prostate volumes $\geq 50 \mathrm{~cm}^{3}$ : Dosimetric analysis of implant quality. Int J Radiat Oncol Biol Phys 2000, 46:1199-1204.

22. Landis DM, Schultz D, Cormack R, Tempany C, Beard C, Hurwitz M, O'Leary M, Albert M, Valentine K, D'Amico AV: Acute urinary retention after magnetic resonance image-guided prostate brachytherapy with and without neoadjuvant external beam radiotherapy. Urology 2005, 65:750-754.

23. Thomas MD, Cormack R, Tempany CM, Kumar S, Manola J, Schneider L, Hurwitz MD, D'Amico AV: Identifying the predictors of acute urinary retention following magnetic-resonance guided prostate brachytherapy. Int J Radiat Oncol Biol Phys 2000, 47:905-908.

24. Khoo ELH, Schick K, Plank AW, Poulsen M, Wong WW, Middleton M, Martin JM: Prostate contouring variation: can it be fixed? Int J Radiat Oncol Biol Phys 2012, 82:1923-1929.

25. Park SB, Kim JK, Choi SH, Noh HN, Ji EK, Cho KS: Prostate volume measurement by TRUS using heights obtained by transaxial and midsagittal scanning: comparison with specimen volume following radical prostatectomy. Korean J Radiol 2000, 1:110-113.

26. Murphy G, Haider M, Ghai S, Sreeharsha B: The expanding role of MRI in prostate cancer. Am J Roentgenol 2013, 201:1229-1238.

27. Cheng D, Tempany CMC: MR imaging of the prostate and bladder. Semin Ultrasound CT MR 1998, 19:67-89.

\section{doi:10.1186/1748-717X-9-200}

Cite this article as: Murciano-Goroff et al:: Variability in MRI vs.

ultrasound measures of prostate volume and its impact on treatment recommendations for favorable-risk prostate cancer patients: a case series. Radiation Oncology 2014 9:200.

\section{Submit your next manuscript to BioMed Central and take full advantage of:}

- Convenient online submission

- Thorough peer review

- No space constraints or color figure charges

- Immediate publication on acceptance

- Inclusion in PubMed, CAS, Scopus and Google Scholar

- Research which is freely available for redistribution 